\title{
Towards the rational design of the Py5-ligand framework for ruthenium-based water oxidation catalysts
}

\author{
Schilling, Mauro ; Böhler, Michael ; Luber, Sandra
}

\begin{abstract}
In order to rationally design water oxidation catalysts (WOCs), an in-depth understanding of the reaction mechanism is essential. In this study we showcase the complexity of catalytic water oxidation, by elucidating how modifications of the pentapyridyl (Py5) ligand-framework influence the thermodynamics and kinetics of the process. In the reaction mechanism the pyridine-water exchange was identified as a key reaction which appears to determine the reactivity of the Py5-WOCs. Exploring the capabilities of in silico design we show which modifications of the ligand framework appear promising when attempting to improve the catalytic performance of WOCs derived from Py5.
\end{abstract}

DOI: https://doi.org/10.1039/c8dt01209a

Posted at the Zurich Open Repository and Archive, University of Zurich ZORA URL: https://doi.org/10.5167/uzh-162383

Journal Article

Accepted Version

Originally published at:

Schilling, Mauro; Böhler, Michael; Luber, Sandra (2018). Towards the rational design of the Py5-ligand framework for ruthenium-based water oxidation catalysts. Dalton Transactions, 47(31):10480-10490.

DOI: https://doi.org/10.1039/c8dt01209a 


\title{
Journal Name
}

\section{ARTICLE TYPE}

Cite this: DOI: $10.1039 / x x x x x x x x x x$

\section{Towards the Rational Design of the Py5-Ligand Framework for Ruthenium-Based Water Oxida- tion Catalysts ${ }^{\dagger}$}

\author{
Mauro Schilling ${ }^{a \ddagger}$, Michael Böhler ${ }^{a \ddagger}$, and Sandra Luber ${ }^{a *}$
}

Received Date

Accepted Date

DOI: 10.1039/xxxxxxxxxx

www.rsc.org/journalname
In order to rationally design water oxidation catalysts (WOCs), an in-depth understanding of the reaction mechanism is essential. In this study we showcase the complexity of catalytic water oxidation, by elucidating how modifications of the pentapyridyl (Py5) ligand-framework influence the thermodynamics and kinetics of the process. In the reaction mechanism the pyridine-water exchange was identified as a key reaction which appears to determine the reactivity of the Py5WOCs. Thereby we identify a key feature - namely the pyridine-water exchange which appears to determine the reactivity of WOCs. Exploring the capabilities of in silico design we show which modifications of the ligand framework appear promising when attempting to improve the catalytic performance of WOCs derived from Py5.

\section{Introduction}

The advancements over the last centuries have brought along many technological marvels, a higher standard of living and a vast, world-wide economy which jointly resulted in an unprecedented flourishment of mankind. However, every day an enormous amount of energy is expended to maintain and extend our civilization. To satisfy its enormous demand for energy mankind heavily relies on fossil fuels. Due to the projected depletion of easily accessible fossil fuel reserves, an energy shortage is expected towards the end of the century. As a consequence, scientists and entrepreneurs around the globe have started to explore alternative energy sources. The most potent and reliable source of energy on earth is sunlight.. However, harvesting, and particularly, the transportation and storage of solar energy pose major technological challenges. Conversion of solar energy into chemical energy by photocatalytic water-splitting promises to play an essential role in surmounting these problems. The reaction consists of two parts: the oxidation of water to form $\mathrm{O}_{2}$ and the reduction of water (or its protons) to form $\mathrm{H}_{2}$. This work is concerned with the oxidation of water to molecular oxygen, which remains a bottle-neck for artificial water-splitting. The reaction is associated a large reduction potential of $1.23 \mathrm{~V}$ relative to the normal hydrogen electrode (NHE):

\footnotetext{
${ }^{a}$ University of Zurich, Department of Chemistry C Winterthurerstrasse, 190, CH-8057 Zurich, Switzerland. Fax: +41 4463568 13; Tel: +41 4463544 21; E-mail: sandra.luber@chem.uzh.ch

$\dagger$ Electronic Supplementary Information (ESI) available: [details of any supplementary information available should be included here]. See DOI: 10.1039/b000000x/ $\ddagger$ These authors contributed equally to this work.
}

$$
2 \mathrm{H}_{2} \mathrm{O} \longrightarrow \mathrm{O}_{2}+4 \mathrm{H}^{+}+4 \mathrm{e}^{-} \quad E_{\text {red }}^{\circ}=1.23 \mathrm{~V}
$$

Water oxidation catalysts (WOCs) containing ruthenium have been used from the very beginning of this research area. In fact, the very first non-natural WOC was a dinuclear ruthenium complex termed the 'blue dimer' ([(bpy) $\left.)_{2}\left(\mathrm{H}_{2} \mathrm{O}\right) \mathrm{RuORu}\left(\mathrm{H}_{2} \mathrm{O}\right)(\text { bpy })_{2}\right]^{4+}$, bpy $=$ bipyridine $) .^{1}$ While it was initially believed that polynuclearity is a keyrequirement for WOCs, ${ }^{2-5}$ later studies revealed that mononuclear ruthenium complexes were also capable of catalyzing the reaction. ${ }^{6-9}$ Since then, these mononuclear catalysts have seen a tremendous research interest and a variety of systems have been proposed. ${ }^{10-17}$ Naturally, for such a complex catalysis consisting of several different steps (including deprotonations, oxidations, association of water, displacement of dioxygen, and so forth) the behavior among the proposed catalysts differs and various bottlenecks exist. ${ }^{5,18,19}$ In the catalytic cycles as shown in Figure 1, the steps are usually categorized into three phases: water activation, oxygen-oxygen bond formation, and oxygen evolution. The initial water activation prepares the water molecule via a sequence of an association of water, proton coupled electron transfers (PCETs) and oxidations to form the oxygen-oxygen bond.

After the $\mathrm{O}-\mathrm{O}$-bond formation, the final $\mathrm{O}_{2}$-evolution phase consists of rearrangements (and PCET) which lead to the dissociation of an oxygen molecule.

The main distinction between the mechanisms of water oxidation (using mononuclear catalysts) is whether the $\mathrm{O}-\mathrm{O}$ bond is formed via a water-nucleophilic attack (WNA) or an interaction of two metal-oxo species (I2M) (Figure 1). ${ }^{2}$ 


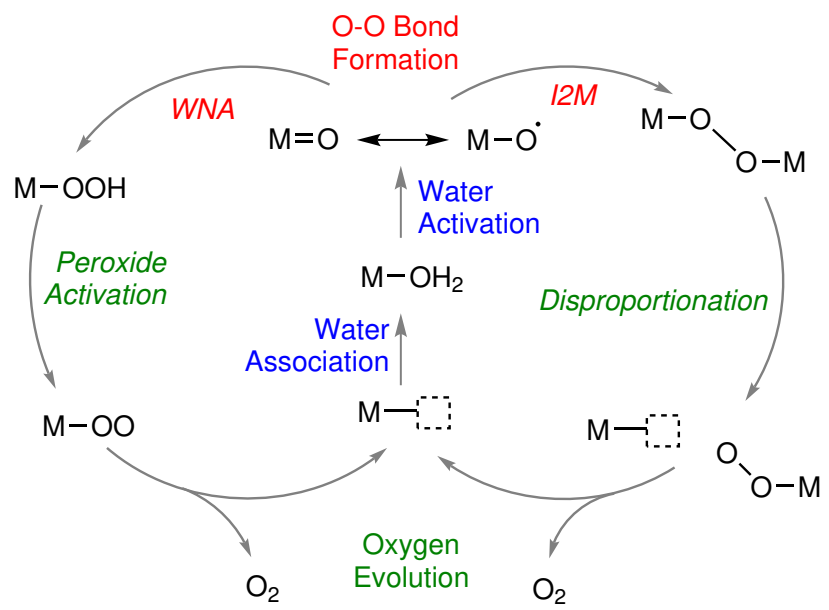

Fig. 1 Catalytic cycles for water oxidation. The steps in the cycle are often divided into phases. Water-nucleophilic attack cycle on the left, radical coupling cycle on the right. The scheme is conceptually inspired by Shaffer et al. as well as Schilling and Luber. ${ }^{2,20}$

In the WNA pathway, a $\mathrm{Ru}=\mathrm{O}$ species (commonly with ruthenium in oxidation state $\mathrm{V}$ ) is attacked by a water molecule, which loses a proton in this process. This step is usually associated with a large energy barrier due to the weak nucleophilicity and acidity of water. To overcome this limitation, incorporation of ('dangling') bases has become a key paradigm in catalyst design. ${ }^{2,21,22}$ In the radical-coupling mechanism on the other hand, two metaloxo species (also usually in oxidation state V) need to interact with one another. In principle there should be no intrinsic barrier associated with a radical coupling reaction. ${ }^{23}$ However this is not the case, the reason for this lays in the formation of the productive encounter complex, the feasibility of which is determined by intermolecular interactions. To speed up the reaction, systems have been designed which should favor the association of two such metal-oxo units. ${ }^{24-26}$

In numerous examples it has been shown that the choice of the ligand framework allows to switch between the two possible mechanisms. Thereby even small changes which primarily affected the sterics turned out be crucial. ${ }^{27-29}$

Together with our experimental collaborators we have recently studied a series of mononuclear ruthenium-based WOCs which possess an intramolecular base in form of a dangling pyridine. ${ }^{30,31}$ The pentapyridyl (Py5) ligand-framework of those catalysts is composed of two biypyridine subunits (bipy) as well as a pyridine (py) unit liked together at an $s p^{3}$ carbon. The substitution at the latter (either a methyl or a methoxy group) was the sole structural difference between the studied catalysts. However, quite a different behavior was observed experimentally for the two ligand frameworks (see Figure 2). In an attempt to rationalize those different reactivities (turnover frequency (TOF) (Py5OMe/Py5Me) $\approx 180$, turnover number (TON) (Py5OMe/Py5Me) $\approx 36$ ), compared the thermodynamic properties of a proposed water oxidation cycle as well as the energy barriers for the WNA. ${ }^{30}$ It was found that both the thermodynamics to reach the catalytically active $\mathrm{Ru}(\mathrm{V})=\mathrm{O}$ as well as the kinetics of the WNA are similar for both catalysts. Inspired by this curiosity, we further investigated those catalysts. In this manuscript we focus our attention in particular on the ligand framework and how it affects the catalytic performance.

The idea behind this was not only to further elucidate experimental findings but also to deduce design guidelines to further improve the catalysts. This computational work is structured as follows: First, we will discuss the Py5-ligand framework, its coordination mode and the resulting isomers. In the second part we focus on the water oxidation mechanism, and in particular on the $\mathrm{O}-\mathrm{O}$ bond formation by a WNA. Finally, in the last part we explore modifications of the ligand framework and how they affect different parts of the catalytic cycle.
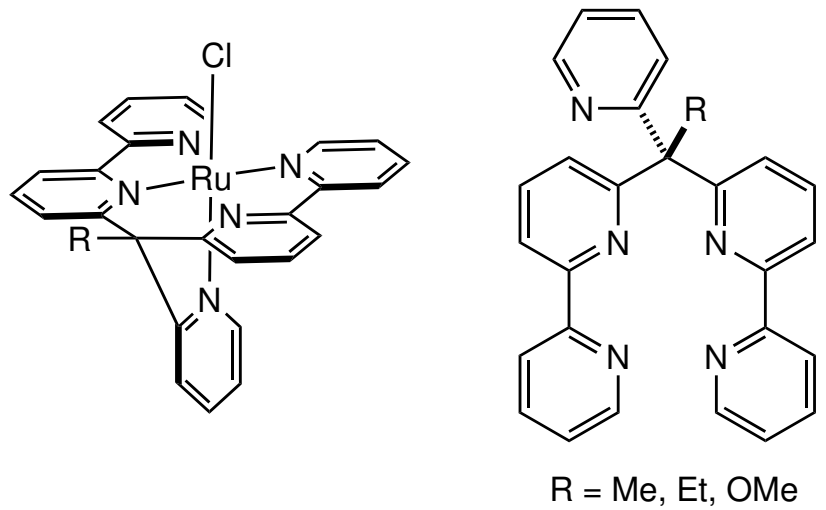

Fig. 2 Schematic drawing of the Py5 derived Ru-based WOCs studied in this work.

\subsection{Methods}

All calculations were carried out using Kohn-Sham density functional theory (KS-DFT) as implemented in the Turbomole software package ${ }^{32}$ (version 7.0). In general, structure were optimized employing BP86-D3/def2-TZVP, and electronic energies were obtained at the B3LYP-D3/def2-TZVP/COSMO level of theory. An exhaustive description of the settings and the protocols employed can be found in the $\mathrm{ESI}^{\dagger}$. The caption of all figures and tables includes a description of the level of theory employed. If not explicitly stated otherwise, all reported energies are Gibbs free energies in $\mathrm{kcal} \mathrm{mol}^{-1}$.

\section{Results and Discussion}

As laid out in the introduction, the objective of this work is to get a better understanding of the Py5 ligand framework, in order to derive design guidelines on how to improve Py5 containing WOCs.

\subsection{Water Association}

From experiments it is known that the Py5 ligand framework can arrange in a cis or trans fashion (relative orientation of bipy fragments) where by the trans-bipy isomer was found to be the dominant one. ${ }^{30,33}$ In our previous work we have established that the differences in catalytic efficiency (TON/TOF) between the Py5Me and Py5OMe ligand framework are unlikely to be caused by the thermodynamic energy differences on the path to the catalytically 
active $\mathrm{Ru}(\mathrm{V})$-oxo or the barrier for the WNA afterwards.

The focus of this work is therefore primarily on the initial steps of the catalytic mechanism, namely the association of a water ligand. ${ }^{30}$ The latter is a prerequisite for water oxidation since the catalyst itself does not bear an aqua ligand. For similar ligand frameworks Sun and co-workers were able to isolate intermediates with a sevenfold coordinated Ru-center. ${ }^{34}$ Such an extension of the coordination sphere makes a ligand dissociation prior to water association unnecessary. However, we (computationally) did not find any stable sevenfold coordination for catalysts derived from the Py5 ligand framework. To the best of our knowledge, there is no experimental evidence for a sevenfold coordinated intermediate, therefore we assume that a ligand exchange reaction has to take place. What is more, there is neither an experimental clue nor evidence for a sevenfold coordinated intermediate, therefore, we can safely assume that a ligand exchange reaction needs to take place.

In our previous work we naturally assumed that the pyridine fragment is displaced by a water molecule resulting in a trans alignment (with respect to the chlorido ligand). ${ }^{30}$ This option will be discussed later in detail in section 2.2.3. An alternative pathway involves the displacement of a pyridine subunit of a bipyridyl fragment, the resulting isomers are referred to as cis. These cis structures were found to be 8 to $20 \mathrm{kcal} \mathrm{mol}^{-1}$ higher in energy than their respective trans counterparts, which in turn makes their involvement in the catalytic cycle unlikely (see Figure S1 in $\mathrm{ESI}^{\dagger}$ ). This supports our previous conclusion that the trans isomer is the most likely candidate to undergo water oxidation. Nevertheless, there are two interesting points to note. Firstly, it appears that these cis structures are generally slightly more acidic. As can be inferred from the more frequent intramolecular proton transfers during geometry optimizations, which lead to a release of sterical strain in the structure. Secondly, the cis-Ru(V)=O structure fundamentally differs from trans- $\mathrm{Ru}(\mathrm{V})=\mathrm{O}$ in that the oxygen has been subjected to a nucleophilic attack by a pyridine fragment giving rise to a formal $\mathrm{N}-\mathrm{O}$ bond.

The last option is a water-chlorido exchange. Those structures were also found to be too high in energy in order to contribute to water oxidation catalysis, in part due to their higher charge which renders oxidation reactions energetically more demanding. Furthermore, those trans-aqua-pyridine intermediates are the precursors of bis-aqua isomers. The latter have been found to possess a significantly lower catalytic activity than their chlorido analogues. ${ }^{30}$ This led to the speculation that the bis-aqua isomers are part of a deactivation pathway which results either in inert side-products ore even in the decomposition of the catalyst. Therefore we reached the conclusion that a strong $\mathrm{Ru}-\mathrm{Cl}$ bond is a key requirement to maintain the high catalytic activity of Py5 derived WOCs. This is rather counterintuitive since for similar ruthenium based WOCs, halides such as iodo ligands were found to be especially labile towards ligand exchange reactions. ${ }^{35}$ Note, Py5 bearing WOCs do require a halide as spectator ligand, while for many other WOCs the halides are mere placeholders for the substrate to coordinate the metal center. The experimental rates for the chlorido-water exchange were found to be one order of magnitude larger for Py5Me compared to Py5OMe. ${ }^{30}$ Those dif- ferences can not be fully explained based on the thermodynamics which are similar for both ligands.

For a more complete picture, the concerted transition states of the chlorido-water exchange reaction were modeled employing the same computational procedure as for the WNA-TS (Figure 3). The obtained transition state energies range from 21 to $25 \mathrm{kcal} \mathrm{mol}^{-1}$ for $\mathrm{Ru}(\mathrm{II})$ and 25 to $29 \mathrm{kcal} \mathrm{mol}^{-1}$ for $\mathrm{Ru}(\mathrm{III})$, respectively (see Table 1). Unlike the thermodynamic which suggests that there is no significant difference between the two ligands Py5OMe and Py5Me, the activation barriers tell a different story. The barriers for Py5Me are independent of the oxidation state about $4 \mathrm{kcal} \mathrm{mol}^{-1}$ smaller than the respective Py5OMe barriers. This observation allows finally to rationalize the above mentioned experimentally observed differences. ${ }^{30}$

\begin{tabular}{lr}
\hline Variant & TS \\
\hline Ru(II)Py5OMe & 25.3 \\
Ru(III)Py5OMe & 29.0 \\
Ru(II)Py5Me & 20.9 \\
Ru(III)Py5Me & 25.1 \\
\hline Ru(III)Py5OMe-pOMe & 28.8 \\
Ru(III)Py5OMe-pNO 2 & 29.2 \\
\hline
\end{tabular}

Table 1 Activation energies $\left(\mathrm{kcal} \mathrm{mol}^{-1}\right)$ of the concerted chlorido-water exchange, relative to the energy of the respective chlorido-species and a water molecule. Energies were obtained at the B3LYP-D3/def2TZVP/COSMO level of theory.

Additionally, the dissociative pathway was modeled for the $\mathrm{Ru}(\mathrm{III})$ species, where energy differences between the two ligand frameworks were found to be as close as $1.6 \mathrm{kcalmol}^{-1}$. These intermediates are approximately $10 \mathrm{kcal} \mathrm{mol}^{-1}$ higher in energy than the concerted transition state, which renders them chemically unimportant. In a similar study the ligand exchange reaction on Ru-aqua ions were investigated, where both the dissociative and the interchange (concerted) mechanism were found to be feasible depending on the oxidation state of the metal center. ${ }^{36}$ This might be explained by the rigidity of the Py5 ligand framework which cannot adopt to the under-coordinated metal center in the dissociative pathway as easily as aqua ligands. This leaves the concerted mechanism as the sole feasible pathway for a chlorido-water exchange.

Having identified a key difference between the two ligands we were interested whether the $\mathrm{Ru}-\mathrm{Cl}$ bond could be altered by introducing substituents at the pyridine fragment trans to the halide. Therefore, activation barriers were calculated for catalysts, where a nitro or methoxy group was introduced in para position of the pyridine fragment in order to electronically alter the $\mathrm{N}-\mathrm{Ru}$ bond. Different substitution patterns are possible, however in order to keep electronic and steric effects separated substitutions in the para position are presented. However, those changes had a minor influence on the energetics of the transition states (see Figure 3). 

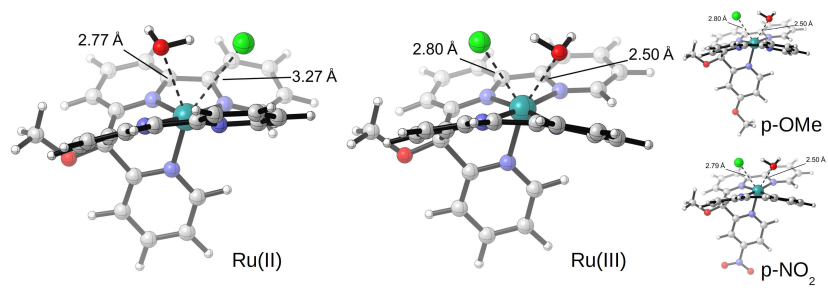

Fig. 3 Transition states for chloride displacement in Py50Me with Ruthenium in oxidation state II or III assuming that the process is concerted. Note that the positions of chloride and water are interchanged for $\mathrm{Ru}(\mathrm{II})$ and $\mathrm{Ru}(\mathrm{III})$, this is not a computational result but a consequence of different starting guesses. Structures were were optimized at the BP86D3/def2-TZVP level of theory.

\subsection{Water Oxidation Mechanism}

Having established which isomers contribute to the catalytic performance, we now devote our attention to the thermodynamics and kinetics of the water oxidation mechanism itself.

\subsubsection{Water Activation}

In our previous study we established that the thermodynamics of the water-oxidation cycles up to the $\mathrm{Ru}(\mathrm{V})$ oxidation state are virtually identical for both ligands Py5OMe and Py5Me. This is with the exception of the substitution of pyridine ligand with a water molecule, which differs significantly. ${ }^{30}$ Those findings indicate that the two ligands most likely distinguish themselves in terms of their electronics but mainly in the sterical demand of their substituents. To further elucidate this assumption we performed the same analysis of both thermodynamics and kinetics for the hypothetical ethyl-analogue (Py5Et) of the Py5 ligand framework, which we assumed would impose sterical restrictions more similar to those of the Py5OMe ligand, while being electronically close to Py5Me. The energies obtained with this hypothetical ligand are given in Figure 4. As conjectured, they are in essence identical with the Py5OMe and Py5Me containing complexes, except for the pyridine-water substitution where the energies lay approximately in between the other two ligands (see Table S1 in ESI ${ }^{\dagger}$ ). Adding to the discussion of the previous section, the energies calculated for the thermodynamics of the chlorido-exchange of Py5Et are in between the ones of Py5OMe, and Py5Me, which highlights the similarity of those ligands (see Table S1 in ESI ${ }^{\dagger}$ ). It also points out that, at least for the thermodynamics, sterics plays a negligible role. On the other hand, sterics might play a crucial role in the water-association (see Figure 5). In the Py5OMe ligand the interactions between the oxygen and the bipyridyl fragments are negligible compared to the strong methyl-bipy interactions in the case of Py5Me, which originate from the proximity of the hydrogen atoms to the bipyridyl fragments. From this observation, differences in terms of thermodynamics and kinetics might be expected in reactions involving the mentioned site. However, experimentally the rates for pyridine-water exchange were found to be virtually identical. ${ }^{30}$ The discrepancy between theory and experiments might be manifold, starting form the simplified computational model system which neglects any kind of hydrogen bonding with the solvent, ending at the experimental techniques and fitting procedures, which are all prone to uncertainties.

\subsubsection{Oxygen-Oxygen Bond Formation}

Since the ethyl substitution did not significantly alter the thermodynamics, we further investigated its influence on the kinetics of the WNA, by modeling the relevant transition states. A key requirement for modelling these TS states is the inclusion of an additional explicit solvent molecule which forms a hydrogen bond with the nucleophile (see Figure 6). The necessity to include explicit solvent molecules for WNA transition states was also observed by others (see for example $29,37,38$ ). For a more detailed validation of the explicit solvation model for the transition state, we refer to the $\mathrm{ESI}^{\dagger}$ section and in particular to Table S2 and Figure S2.

Unsurprisingly the activation barrier for the hypothetical Py5Et ligand matches the ones calculated for the Py5OMe/Py5Me ligands (see Table 2), further supporting our conclusion that substitutions at the $s p^{3}$ carbon do not significantly affect the water oxidation reaction mechanism, neither from a thermodynamical nor from a kinetic point of view.

\begin{tabular}{lrrr}
\hline Variant & AR & TS & AP \\
\hline Py5OMe $^{1}$ & 7 & 16 & 6 \\
Py5Me $^{1}$ & 5 & 14 & 9 \\
Py5Et & 7 & 14 & 9 \\
\hline
\end{tabular}

Table 2 Energies $\left(\mathrm{kcalmol}^{-1}\right)$ of WNA structures with Py5 ligand containing two explicit water molecules. AR = associated reactants, TS = transition state, $\mathrm{AP}=$ associated products. Energies were obtained at the B3LYP-D3/def2-TZVP/COSMO level of theory. 1: Energies published by Gil-Sepulcre et al. ${ }^{30}$

\subsubsection{The Crucial Step - Replacing Pyridine by Water}

In this section, we discuss the step which, besides from the chlorido-water exchange, is the most interesting one in order to differentiate between Py5OMe and Py5Me: the water association. We will refrain from further discussing the Py5Et ligand since we have shown that its energetics with respect to thermodynamics and kinetics of a WNA is in between the one for the Py5OMe and Py5Me ligands.

To further elucidate the nature of pyridine-water exchange we turned to relaxed (geometry optimized) bond dissociation scans of the $\mathrm{Ru}-\mathrm{N}_{\text {pyridine }}$ and $\mathrm{Ru}-\mathrm{O}_{\text {water }}$ bonds (see $\mathrm{ESI}^{\dagger}$ for a description of the protocol). The respective starting points of the scans were chosen to be $\mathrm{N}^{5}-\mathrm{Ru}$ (II) $-\mathrm{Cl}$ and $\mathrm{N}^{4}-\mathrm{Ru}(\mathrm{II})-\mathrm{OH}_{2}-\mathrm{Cl}$ referred to as $\mathrm{Py}_{5} \mathrm{OMe}-\mathrm{Cl}$ and $\mathrm{Py}_{5} \mathrm{Me}-\mathrm{Cl}$, respectively. For both species, the bonds were scanned in a dissociative manner as depicted in Figure 7. The $\mathrm{Ru}-\mathrm{N}_{\text {pyridine }}$ bond dissociation is more easily achieved for Py5OMe than for Py5Me (see Figure 8). In contrast to this, the $\mathrm{Ru}-\mathrm{OH}_{2}$ dissociation appears to be more favorable for Py5Me than for Py5OMe (Figure 9). This observation mirrors the thermodynamics where the water association is much more favored for Py5OMe (easier pyridine displacement, harder dissociation of water). Furthermore, for all trans-aqua complexes (denoted as $\mathrm{Py}_{5} \mathrm{Me}-\mathrm{H}_{2} \mathrm{O}$ and $\mathrm{Py}_{5} \mathrm{OMe}-\mathrm{H}_{2} \mathrm{O}$ ) dissociation of either the water ligand or the pyridine becomes more difficult due to the higher charge of the system which leads to strengthening 


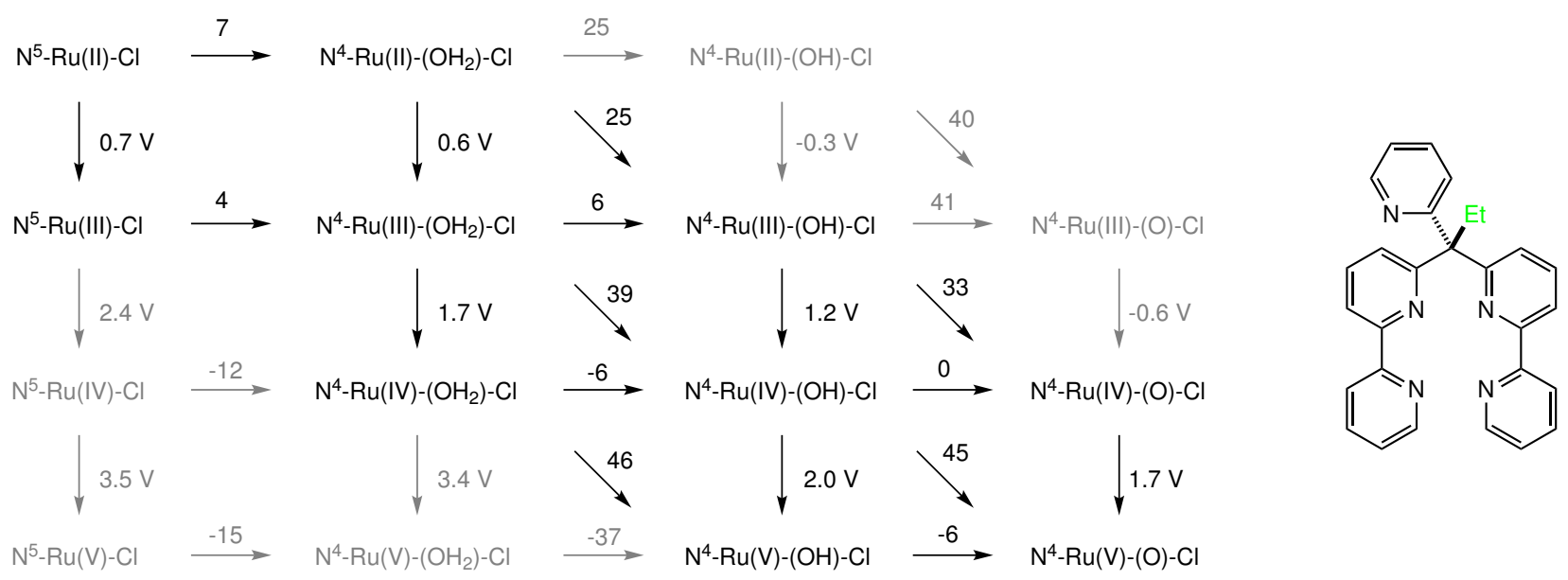

Fig. 4 Thermodynamic table up to $\mathrm{Ru}(\mathrm{V})=\mathrm{O}$ for Py5Et containing complex. Horizontal arrows represent water association (first) or deprotonations (in $\mathrm{kcal} \mathrm{mol}^{-1}$ ), diagonal arrows stand for PCETs (in $\mathrm{kcal} \mathrm{mol}^{-1}$ ), vertical ones represent reduction potentials given in $\mathrm{V}$. Note that $\mathrm{Et}-\mathrm{N}^{4}-\mathrm{Ru}(\mathrm{IV})-\left(\mathrm{OH}_{2}\right)-\mathrm{Cl}, \mathrm{Et}-\mathrm{N}^{4}-\mathrm{Ru}(\mathrm{V})-\left(\mathrm{OH}_{2}\right)-\mathrm{Cl}$ and $\mathrm{Et}-\mathrm{N}^{4}-\mathrm{Ru}(\mathrm{V})-(\mathrm{OH})-\mathrm{Cl}$ are $\mathrm{N}-\mathrm{H}$ acidic due to a proton transfer from the oxygen to pyridine nitrogen. Structures associated with deprotonation energies larger than $20 \mathrm{kcal} \mathrm{mol}^{-1}$ and reduction potentials larger than $2.0 \mathrm{~V}$ have been deemed unlikely and marked in gray. Energies were obtained at the B3LYP-D3/def2-TZVP/COSMO level of theory.
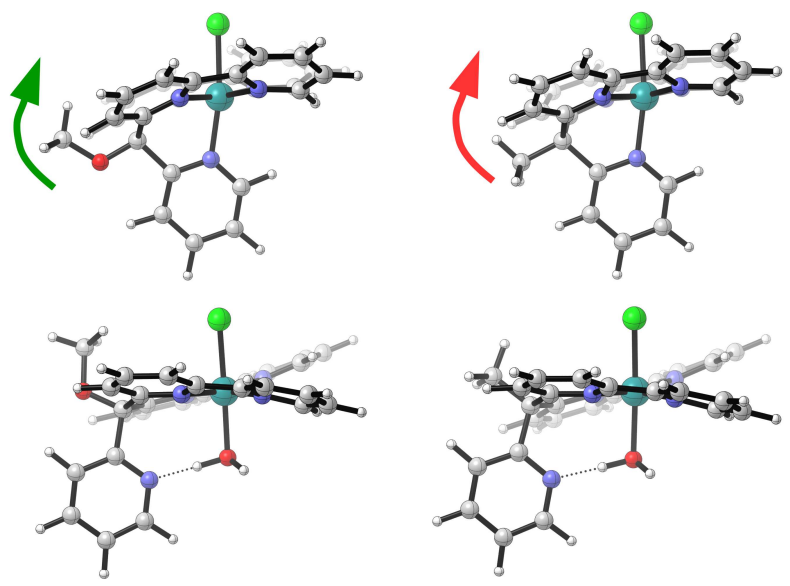

Fig. 5 Illustration of the sterical interaction which occurs upon pyridine dissociation for the Py5OMe ligand (left column) and the Py5Me ligand (right column). Note how the methoxy group gives lower dissociation energies because the sterical bulk is further away and does not interact as strongly with the bipyridine framework as the methyl substituent does. The same is true for the ethyl substituent.

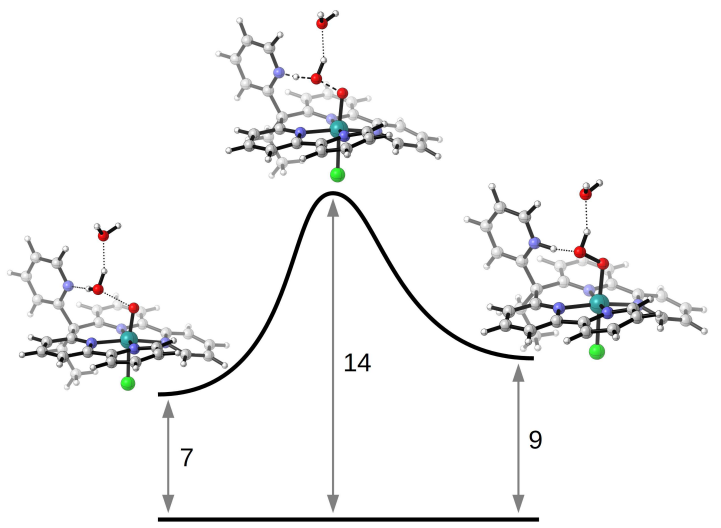

Fig. 6 Transition-state and WNA-path for $\mathrm{Et}-\mathrm{N}^{4}-\mathrm{Ru}(\mathrm{V})-\mathrm{O}-\mathrm{Cl}(\mathrm{Py} 5 \mathrm{Et})$. Energies given in $\mathrm{kcalmol}^{-1}$. Energies were obtained at the B3LYP. D3/def2-TZVP/COSMO level of theory based on structures optimized at BP86-D3/def2-TZVP. 
of the $\mathrm{Ru}-\mathrm{N}$ respectively $\mathrm{Ru}-\mathrm{OH}_{2}$ bond. In the case of the trans aqua complexes, there is a small kink around $2.8 \AA$, which is a computational artefact caused by the constrained $\mathrm{Ru}-\mathrm{N}$ bond, resulting from a rotation of the $\mathrm{R}-\mathrm{C}-\mathrm{Py}(\mathrm{R}=\mathrm{Me}, \mathrm{OMe})$ fragment or a rotation along the $\mathrm{C}-\mathrm{Py}$ bond.
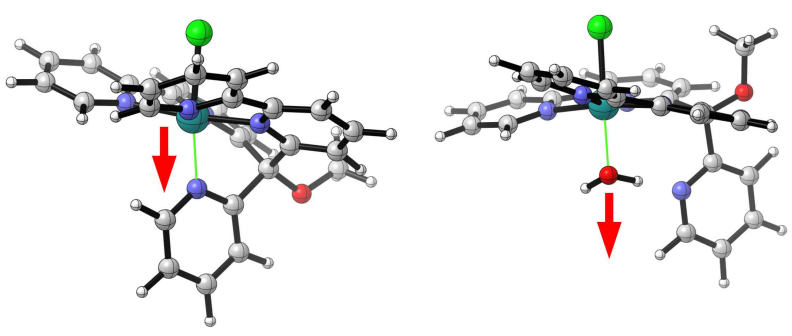

Fig. 7 Indicated bonds in green were scanned: dissociation of $\mathrm{Ru}-\mathrm{N}_{\text {pyridine }}$ on the left and $\mathrm{Ru}-\mathrm{O}_{\text {water }}$ on the right.

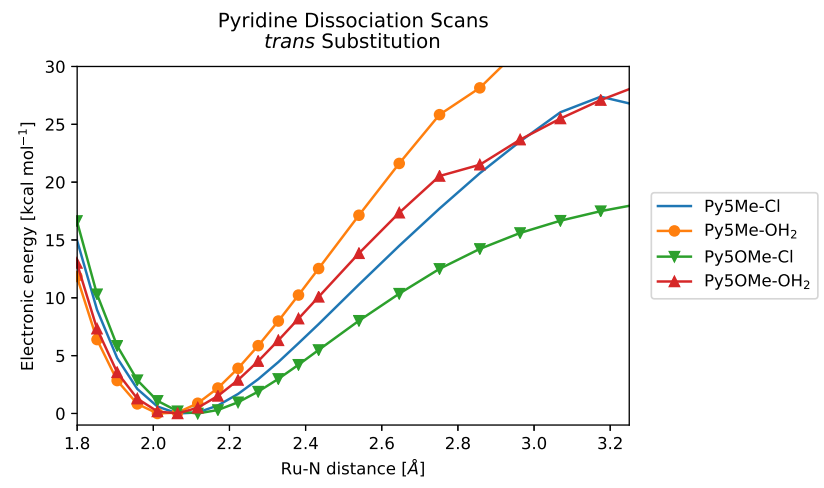

Fig. 8 Scans of the $\mathrm{Ru}-\mathrm{N}$ bond length (dissociation of pyridine), electronic energy in $\mathrm{kcalmol}^{-1}$, distance in $\AA$. Chlorido or water ligand in trans position to pyridine. Energies were obtained at the B3LYP-D3/def2TZVP level of theory based on constrained geometries optimized employing BP86-D3/def2-SVP.

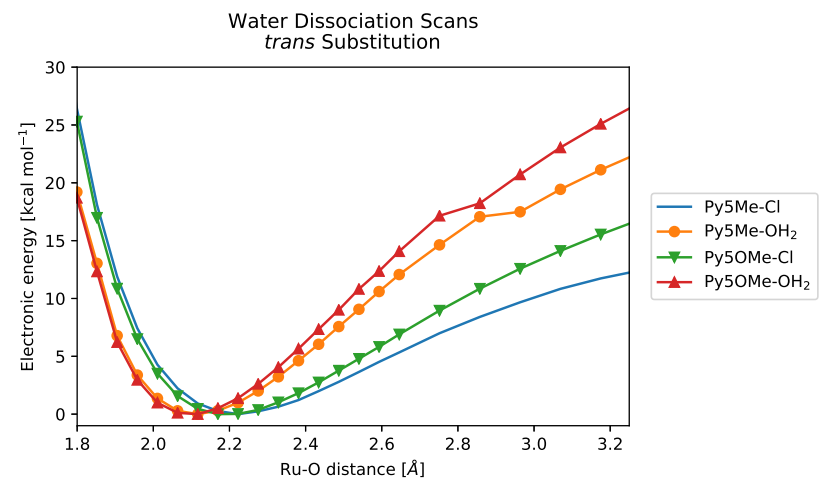

Fig. 9 Scans of the $\mathrm{Ru}-\mathrm{O}$ bond length (dissociation of water), electronic energy in $\mathrm{kcal} \mathrm{mol}^{-1}$, distance in $\AA$. Energies were obtained at the B3LYP-D3/def2-TZVP level of theory based on constrained geometries optimized employing BP86-D3/def2-SVP.

\subsection{Towards Ligand Design: Modification of the Axial Pyri- dine}

As discussed in the previous section (2.2.3), the displacement of pyridine by water is probably the crucial step influencing the reactivity of the catalyst. Therefore altering the dissociation behavior of the $\mathrm{Ru}-\mathrm{N}$ bond, which is governed by both sterical and electronic contributions, might be a good starting point to improve the overall catalytic performance. For the chlorido-water exchange, substitutions on the pyridine fragment turned out to have only a minor influence on the transition state and its energetics (see section 2.1). However for this reaction the pyridine is merely a spectator. A significant influence is expected only for reactions where the pyridine is directly involved. Combining the two concepts established in the previous sections, namely, bond-dissociation scans as well as small chemical modifications in the ortho, meta or para position of the axial pyridine, gives further insight into the behavior of the ligand framework.

\subsubsection{Tuning the Water Association}

First of all, the thermodynamics of the water-association reaction was investigated for a series of different modifications on the pyridine unit (see Table 3). Surprisingly, apart from para- $\mathrm{CF}_{3}$ and para-CN, all substituents lead to a more exergonic waterassociation reaction compared to the unmodified ligand. The largest effects can be observed with substituents in ortho position because of their large sterical and electronic impact. The influence of meta and para substituents on the water-association is probably negligible as seen by the rather small energy differences compared to the unmodified ligand. Theortho substituents ordered by their decreasing influence are: $(\mathrm{t}-\mathrm{Bu})>\mathrm{CF}_{3}>\mathrm{F}>$ $\mathrm{Me}>\mathrm{OMe}>\mathrm{CN}$. Screening of different ligands based on thermodynamic quantities such as dissociation energies has already been successfully applied to improve WOCs (see for example the work of Duan et al.). ${ }^{25,39,40}$

\begin{tabular}{lccc}
\hline Substituent & ortho & meta & para \\
\hline $\mathrm{H}$ (no mod.) & 4.4 & 4.4 & 4.4 \\
$\mathrm{OMe}$ & 3.4 & 4.2 & 4.1 \\
$\mathrm{~F}$ & 2.8 & 4.1 & 3.9 \\
$\mathrm{CF}_{3}$ & -1.7 & 4.2 & 5.0 \\
$\mathrm{CN}$ & 3.7 & 3.7 & 4.9 \\
$\mathrm{Me}$ & 3.0 & - & - \\
$\mathrm{t}-\mathrm{Bu}$ & -6.6 & - & - \\
\hline
\end{tabular}

Table 3 Energies of the water-association reaction at the $\mathrm{Ru}$ (II) oxidation state, given in $\mathrm{kcal} \mathrm{mol}^{-1}$. Modifications on the axial pyridine were introduced at the indicated positions. Energies were obtained at the B3LYPD3/def2-TZVP/COSMO level of theory.

As for the unmodified ligand scans of the $\mathrm{Ru}-\mathrm{N}$ and $\mathrm{Ru}-\mathrm{O}$ bonds were performed, the former are shown in Figures 10 and 11 (the scans for the $\mathrm{Ru}-\mathrm{O}$ dissociation can be found in Figures S3 and S4 $\mathrm{ESI}^{\dagger}$ ). The largest effect was observed with ortho- $\mathrm{CF}_{3}$, where the larger equilibrium bond length and the flatter slope of the dissociation curve suggest weaker bonding. Also fluorine, in ortho position, leads to a relatively small slope compared to 
the unmodified Py5OMe, indicating a weaker bond. However, the effect is apparently not caused by sterics since the equilibrium bond length remains the same. The potential energy curve obtained for a $\mathrm{CH}_{3}$-substituted Py5OMe appears to be shifted towards a larger equilibrium distance, indicating some sterical interactions with the remaining ligand framework. The $\mathrm{CF}_{3}$ modification can be viewed as a combination of the effects exerted by methyl and fluorine substituents since it shifts the bond length and displays a smaller slope than the other modifications. Consequently, all these substituents should lead to a more facile dissociation. In contrast to this, the modifications have very little impact on the water dissociation. This seems reasonable as the hydrogen-bonding capability of the pyridine is not expected to change the $\mathrm{Ru}-\mathrm{O}$ bond strength significantly.

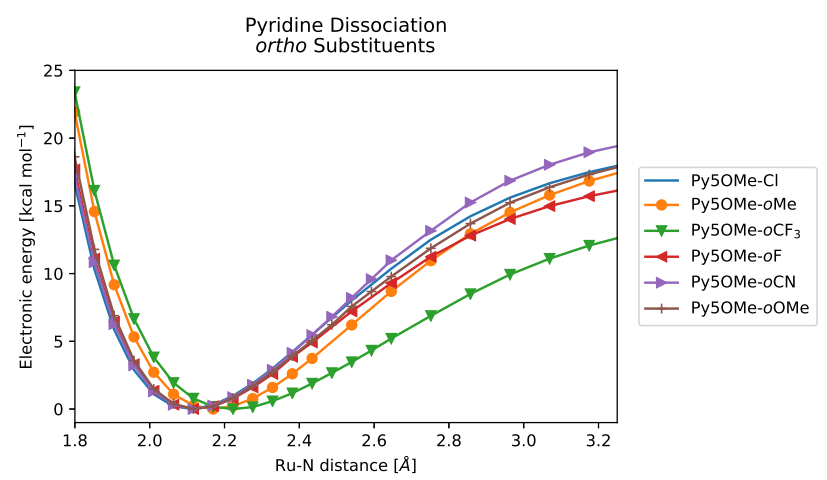

Fig. 10 Pyridine dissociation scans, where the axial pyridine is modified by the indicated substituents in the ortho position, electronic energy in $\mathrm{kcal} \mathrm{mol}^{-1}$, distance in $\AA$. Energies were obtained at the B3LYP-D3/def2TZVP level of theory based on constrained geometries optimized employing BP86-D3/def2-SVP.

As in case of the thermodynamics, the influence of meta and para substituents on the dissociation scans shown in Figure 11 and Figure S5 in $\mathrm{ESI}^{\dagger}$ is minor, both for the dissociation of pyridine and water. This demonstrates the small effect that the electronic modifications of the axial pyridine in the meta and para positions have at the bonding in these molecules.

Scans performed for a higher oxidation state, i.e. Ru(III), gave qualitatively the same results, as the general behavior and the ordering of the substituents is conserved (see Figure S6 in $\mathrm{ESI}^{\dagger}$ ).

\subsubsection{Influence of Modifications of the Axial Pyridine on the WNA-TS}

The modifications introduced on the axial pyridine ligand naturally should not only affect the water association reaction but also the WNA. We therefore have calculated the transition states for some of the above mentioned variations (and a few additional ones). The results of those calculations are summarized in Table 4 which confirms that the energies are considerably affected by some of the introduced substituents. Again the largest influence is exerted by the ortho- $\mathrm{CF}_{3}$ substituent which substantially disfavors the WNA transition state as well as the respective product. This observation resembles Sabatier's Principle which states that stabilization of a catalytic intermediate results in a larger barrier for the conversion to the product. ${ }^{41}$ On the other hand,

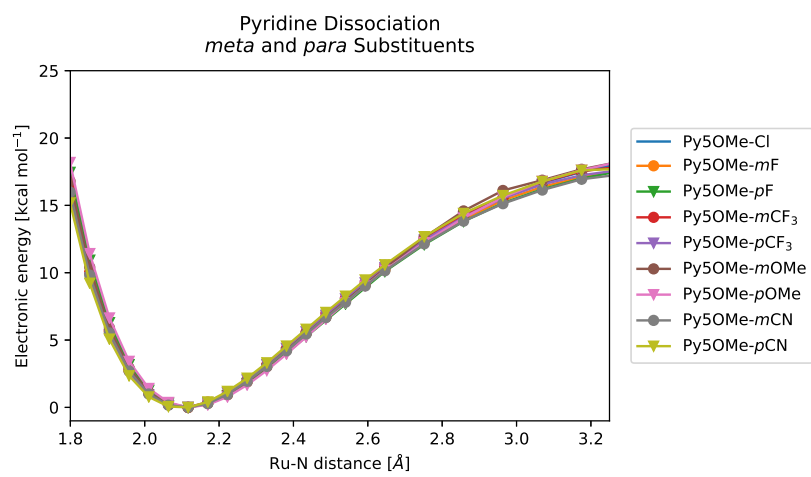

Fig. 11 Pyridine dissociation scans with the indicated substituents in meta or para position of the axial pyridine, electronic energy in $\mathrm{kcal} \mathrm{mol}^{-1}$, distance in $\AA$. Energies were obtained at the B3LYP-D3/def2-TZVP level of theory based on constrained geometries optimized employing BP86D3/def2-SVP.

a methoxy substituent in para position appears to be particularly well suited for promoting the WNA. This is closely linked to the pyridine's increased basicity, which is strongest for para$\mathrm{OMe}$ and favors the formation of a $\mathrm{H}-\mathrm{N}$ bond in the transition state and in the product. Interestingly, many of the substituents lead to somewhat smaller transition state barriers compared to the non-modified pyridine, many in the range of 1 to $2 \mathrm{kcal} \mathrm{mol}^{-1}$ even when the modification makes the pyridine ligand less basic (e.g. ortho- and meta-OMe ${ }^{42}$, para- $\mathrm{CF}_{3}{ }^{43}$ ). However, it can be seen that the basicity plays an important role in the stability of the WNA products (protonated pyridine) and that factors favoring the product decrease the transition state energy. In a similar study Kang et al. calculated activation energies for a series of different ligand frameworks related to the famous Ru-bda (bipyridine-dicarboxylic acid) catalyst by Sun and co-workers. ${ }^{44}$ They report an inverse proportionality between the WNA barrier and the electrophilicity of the metal center. This is not the case for the modification of the Py5 system. However, pyridine is also not expected to affect the electrophilicity of the metal center since it is not directly coordinated to the metal center in the TS.

In Figure 12 the influence of the $\mathrm{OMe}, \mathrm{F}$ and $\mathrm{CF}_{3}$ substituents on the energies (of AR, TS and AP structures) and some properties of the free $\mathrm{Ru}(\mathrm{V})=\mathrm{O}$-complex (Mulliken spin-densities on $\mathrm{Ru}$ and $\mathrm{O}$ and LUMO energies) is shown. Notably, the activation energies decrease for all three substituents going from ortho, meta to para. The strongest energetic effect of the substituents is observed for the AP structure, where a more basic pyridine leads to lower energies. The energy of the TS structure shows an intermediate dependence on the substituent position and basicity, reflecting the partially formed bond, while the associated reactants depend comparably little on the modification. Notice, how the spin-density on Ru is inversely correlated with the activation energy, in contrast to the spin-density on oxygen. The latter intuitively reflects the change of electrophilicity - the less electrons there are on oxygen, the more prone it is to a nucleophilic attack. The correlation can also be seen with the LUMO energy, although the values show only small differences $\left(<3 \mathrm{kcal} \mathrm{mol}^{-1}\right)$. The LUMO is localized entirely on the oxo-ligand, where it acts as 
the accepting orbital for the WNA. ${ }^{45}$ However, these correlations are not necessarily transferable from substituent to substituent, i.e. the changes the spin-density do not quantitatively correlate with the changes in the activation energy etc. Nevertheless, a general energy ordering for the activation energies and product energies of ortho < meta < para can be established, which contrasts with the water-association reaction and showcases the different requirements of the reactions. As stated earlier solvation plays an important role in these reactions, and a different description might alter the obtained trends. Especially the energy from separated to associated reactants is, to a large extent, representing a solvation process. The importance of solvation has also recently been shown for RC mechanism of the WOCs designed by Sun and co-workers, where the oxo-ligand was found to be hydrophobic, thereby favoring the formation of the encounter complex prior to the $\mathrm{O}-\mathrm{O}$ bond formation. ${ }^{46-48}$

Additionally, there is an intramolecular interaction between the electrophilic oxo and the pyridine fragment (denoted as L) in the $\mathrm{L}-\mathrm{N}^{4}-\mathrm{Ru}(\mathrm{V})-\mathrm{O}-\mathrm{Cl}$ structures, i.e. the reference states for AR, $\mathrm{TS}$, and AP (see Table S3 in $\mathrm{ESI}^{\dagger}$ ). The shortest distance among the three substituents $\mathrm{OMe}, \mathrm{F}$, and $\mathrm{CF}_{3}$ at the pyridine is found for the most basic substituent i.e. para-OMe. By adding the water molecules, this interaction is broken up. Its energy is therefore implicitly included in the energy difference between the separated and the associated reactants which may account for some part of the energy differences observed.

\begin{tabular}{llccc}
\hline Substituent & Position & AR & TS & AP \\
\hline unmodified & & 6.8 & 15.6 & 6.2 \\
\hline OMe & ortho & 7.3 & 14.8 & 7.7 \\
& meta & 6.5 & 14.5 & 6.1 \\
& para & 6.2 & 11.7 & 3.2 \\
\hline $\mathrm{F}$ & ortho & 7.2 & 17.1 & 15.5 \\
& meta & 6.8 & 14.7 & 10.4 \\
& para & 6.5 & 13.5 & 7.7 \\
\hline $\mathrm{CF}_{3}$ & ortho & 9.2 & 20.9 & 17.1 \\
& meta & 7.3 & 16.3 & 11.6 \\
& para & 6.5 & 14.8 & 10.3 \\
\hline $\mathrm{NO}_{2}$ & para & 6.8 & 15.3 & 12.0 \\
\hline
\end{tabular}

Table 4 Energies of WNA transition state structures in $\mathrm{kcalmol}^{-1}$. AR $=$ associated reactants, $\mathrm{TS}=$ transition state, $\mathrm{AP}=$ associated products. All energies are given with reference to the free complex and two water molecules. Energies were obtained at the B3LYP-D3/def2TZVP/COSMO level of theory.

\subsubsection{Py5OMe Variant: para-OMe}

As established in the previous section, a methoxy group at the axial pyridine of Py5OMe gives a WNA transition state energy which is lower in energy than the unmodified variant. The waterassociation reaction on the $\mathrm{Ru}$ (II) species is not substantially affected by this modification, as can bee seen from the thermochemical data given in 13. The latter are compared to the unmodified ligand in order to assess the potential this ligand has for catalytic improvements. The water-association reaction on $\mathrm{Ru}(\mathrm{III})$ is fa-

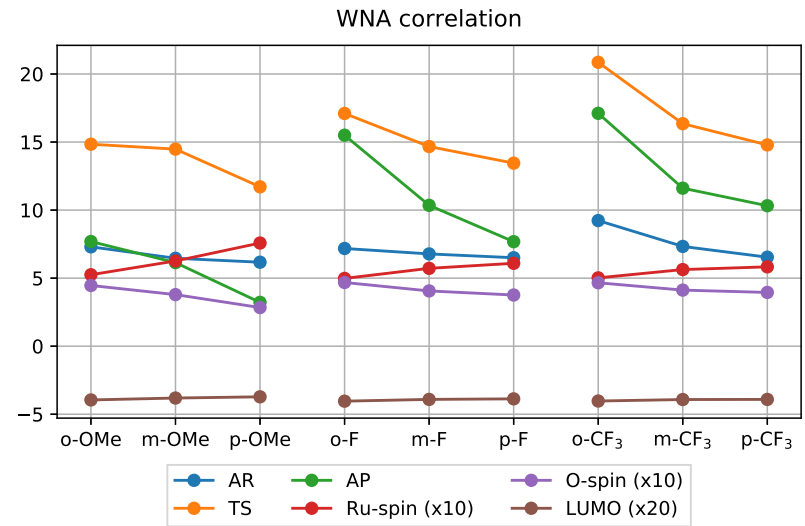

Fig. 12 Correlation of quantities such as energies (AR, TS, AP; $\left.\left[\mathrm{kcalmol}^{-1}\right]\right)$, spin-density on Ru and $\mathrm{O}(\mathrm{x} 10)$ and LUMO energy (x20 $[\mathrm{eV}])$ of the free $\mathrm{Ru}(\mathrm{V})=\mathrm{O}$ species $\left(\mathrm{OMe}-\mathrm{N}^{4}-\mathrm{Ru}(\mathrm{V})-\mathrm{O}-\mathrm{Cl}\right)$ with the position of the substituents on the axial pyridine. Energies were obtained at the B3LYP-D3/def2-TZVP/COSMO level of theory.

vored by approximately $2 \mathrm{kcal} \mathrm{mol}^{-1}$ with respect to the unsubstituted ligand, while the water-association reaction on $\mathrm{Ru}(\mathrm{II})$ is slightly disfavored by $-0.3 \mathrm{kcal} \mathrm{mol}^{-1}$. While we have not generally observed a large dependence of the trends on the oxidation state, this example shows that a substituent can turn from having a slightly detrimental to a positive effect on the thermodynamics. Deprotonation reactions are slightly disfavored compared to the non-modified ligand. However, because of lower reduction potentials for III/II and IV/III couples, the PCET reactions require a similar amount of energy $\left( \pm 2 \mathrm{kcal} \mathrm{mol}^{-1}\right)$. Only the PCET from $\mathrm{Ru}(\mathrm{IV})-\mathrm{OH}$ to $\mathrm{Ru}(\mathrm{V})=\mathrm{O}$ is substantially larger due to the attenuated acidity of the complex. For a conceptional similar system it has been shown that changing the functional group coordinating to the metal center significantly alters the reduction potentials and thereby potentially the catalytic activity. ${ }^{49}$ We further compared the thermodynamics of the whole catalytic cycle with an thermodynamically ideal catalyst as has been done in previous work. ${ }^{47,48,50}$ Here, 'ideal' is meant in the sense that the Gibbs free energy associated with water oxidation (see Equation 1) is equally distributed among four PCETs, thereby minimizing the theoretical overpotential of the reaction. It becomes evident that the introduction of the para-OMe substituent barely affects the thermodynamics - as compared with the unmodified ligand (see Figure 14). This offers the opportunity to selectively alter the strength of the intramolecular base to lower the barrier for the WNA while at the same time keeping the favorable thermodynamics in place.

\section{Summary and Conclusions}

Encouraged by our earlier study on Py5 derived Ru-based WOCs ${ }^{30}$ we further explored the capabilities of the Py5 ligand framework. Clarifying the energetics of different coordination modes (i.e. isomers), we were able to solidify our previous observations based on Py5OMe and Py5Me, namely that they are in essence identical in terms of thermodynamics and kinetics (after the pyridine is replaced by a water molecule). The two ligands are primarily distinguishable by the sterical interaction of their 


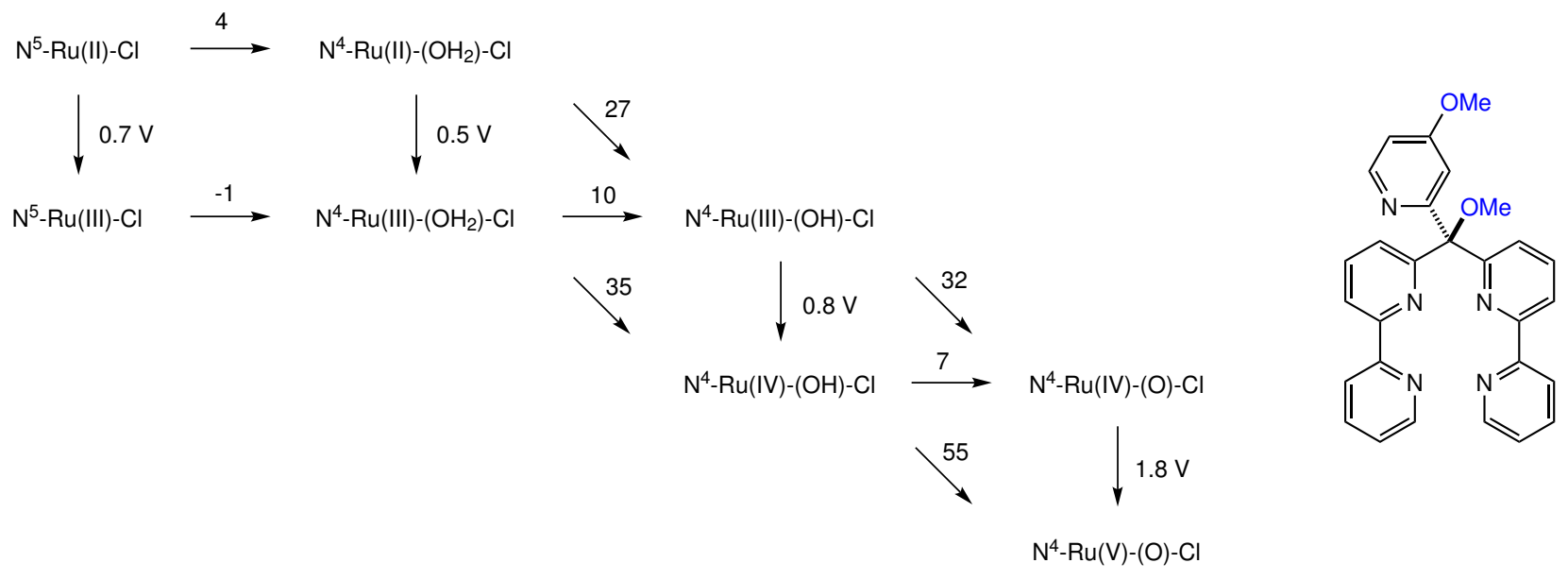

Fig. 13 Energies of the reactions up to $\mathrm{Ru}(\mathrm{V})=\mathrm{O}$ for the para-OMe variant of Py5OMe. Energies are given in kcal mol ${ }^{-1}$. Energies were obtained at the B3LYP-D3/def2-TZVP/COSMO level of theory.

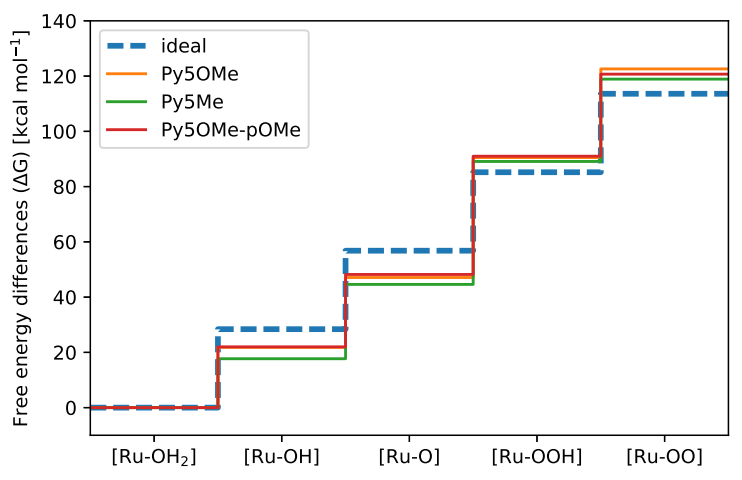

Fig. 14 Thermodynamics of the water oxidation reaction catalyzed by Py5Me, Py5OMe, and Py5OMe variant para-OMe, compared to an 'ideal' catalyst. Energies were obtained at the B3LYP-D3/def2TZVP/COSMO level of theory.

substituents at the $s p^{3}$ carbon. This hypothesis was verified by studying a hypothetical Py5Et ligand. The latter fits perfectly in between the other two in terms of the thermodynamics of the pyridine-water exchange reaction as well as the kinetic barrier for the WNA, establishing the fact that small substituents at $s p^{3}$ carbon do not affect the water oxidation mechanism. The introduction of sterically demanding substituents of course would lead to significant destabilization of the ligand-metal interaction and potentially change in the favored coordination-mode.

Focusing on the initial step prior to the water oxidation cycle, namely association of water to the catalyst, two possible routes were explored - the chlorido-water exchange and the pyridinewater exchange reaction. The first one is possibly part of a deactivation pathway and therefore unlikely part of the catalytic cycle. In agreement with experiments we find a correlation between the substitution of the $s p^{3}$ center and the activation barrier for the chlorido-water exchange. This is rather surprising since the substituent is too far apart to sterically interfere. Nonetheless, the Py5Me derived transition states appear to be much more strained compared to Py5OMe, in part due to the close proximity of the bipyridyl and the methyl. Dissociation scans of both the $\mathrm{Ru}-\mathrm{OH}_{2}$ and the $\mathrm{Ru}-\mathrm{N}$ (pyridine) bonds suggest that modifications of the dangling pyridine may enhance the formation of the catalytically active $\mathrm{Ru}-\mathrm{OH}_{2}$ species. Performing in silico ligand design, we explored the influence of various functional groups and substitution patters on the $\mathrm{Ru}-\mathrm{OH}_{2}$ and $\mathrm{Ru}-\mathrm{N}$ bond. Overall, the $\mathrm{Ru}-\mathrm{OH}_{2}$ bond is not significantly affected by the substitutions at the axial pyridine, while - depending on the position and nature of the substitution - the $\mathrm{Ru}-\mathrm{N}$ bond can be altered efficiently. Those observations are illustrated by the correlation of the relative energies of R, AR, TS, and AP as well as observables from the electronic structure as a function of the substitution pattern. Introducing substituents in the ortho position imposed a sterical penalty which weakens the $\mathrm{Ru}-\mathrm{N}$ bond. A decrease of the basicity caused by electron withdrawing groups further weakens the bond. However, in accordance with Sabatier's Principle we find that those substitutions disfavor the $\mathrm{O}-\mathrm{O}$ bond formation by a WNA. On the other hand, para substituents, which only had a minor influence on the pyridine dissociation, lower the barrier for a WNA. At the same time, the thermodynamics remains virtually unchanged. Those findings suggest that modifying the basicity of the dangling pyridine can be done without disfavoring the other steps of the catalytic cycle. The Py5 system offers even more possibilities for modifications, in particular on the bipy fragments which are directly coordinated to the metal center. Alterations thereof are expected to have more pronounced influence on the thermodynamics of the catalytic cycle - however, the exploration of those modifications was beyond the scope of this work. In this study we made a first step towards in silico design of Py5ligands for water oxidation. A prerequisite for this is an in depth understanding of the catalytic cycle as well potential side reactions (isomerizations, ligand dissociations, etc.). It would be interesting to see whether changing the basicity of intramolecular bases would also primarily affect the WNA barrier in other systems and therefore become a general design concept. 


\section{Conflicts of interest}

There are no conflicts to declare.

\section{Acknowledgments}

We would like thank our collaborators at University of Zurich (UZH) (Cyril Bachmann, Dominik Scherrer, Thomas Fox, Berhard Spingler, Craig J. Richmond and Roger Alberto) and Institute Català d'Investigació Química (ICIQ) (Marcos Gil-Sepulcre, Fernado Bozoglian, Carolina Gimbert-Suriñach, Roger Bofill, Xavier Sala and Antoni Llobet) for the fruitful discussions. The work has been supported by the University of Zurich Research Priority Program "Solar Light to Chemical Energy Conversion" (LightChEC) and the Swiss National Foundation (grant. No. PP00P2_170667). Our calculations have been supported by the Swiss National Supercomputing Center, accounts s745 and s788.

\section{Notes and references}

1 S. W. Gersten, G. J. Samuels and T. J. Meyer, J. Am. Chem. Soc., 1982, 104, 4029-4030.

2 D. W. Shaffer, Y. Xie and J. J. Concepcion, Chem. Soc. Rev., 2017, 46, 6170-6193.

3 M. D. Kärkäs, O. Verho, E. V. Johnston and B. Åkermark, Chem. Rev., 2014, 114, 11863-12001.

4 M. Yamamoto and K. Tanaka, Chempluschem, 2016, 81, 10281044.

5 D. G. H. Hetterscheid and J. N. H. Reek, Angew. Chemie - Int. Ed., 2012, 51, 9740-9747.

6 J. J. Concepcion, J. W. Jurss, J. L. Templeton and T. J. Meyer, J. Am. Chem. Soc., 2008, 130, 16462-16463.

7 I. Lõpez, M. Z. Ertem, S. Maji, J. Benet-Buchholz, A. Keidel, U. Kuhlmann, P. Hildebrandt, C. J. Cramer, V. S. Batista, A. Llobet, I. López, M. Z. Ertem, S. Maji, J. Benet-Buchholz, A. Keidel, U. Kuhlmann, P. Hildebrandt, C. J. Cramer, V. S. Batista and A. Llobet, Angew. Chemie - Int. Ed., 2014, 53, 205209.

8 M. Okamura and S. Masaoka, Chem. - An Asian J., 2015, 10, 306-315.

9 L. Tong, A. K. Inge, L. Duan, L. Wang, X. Zou and L. Sun, Inorg. Chem., 2013, 52, 2505-2518.

10 L. Duan, L. Wang, F. Li, F. Li and L. Sun, Acc. Chem. Res., 2015, 48, 2084-2096.

11 J. D. Blakemore, R. H. Crabtree and G. W. Brudvig, Chemical Reviews, 2015, 115, 12974-13005.

12 M. Schulze, V. Kunz, P. D. Frischmann and F. Würthner, Nat. Chem., 2016, 8, 576-583.

13 M. D. Kärkäs and B. Åkermark, Chem. Rec., 2016, 16, 940963.

14 R. Cao, W. Z. Lai and P. W. Du, Energy Environ. Sci., 2012, 5, 8134-8157.

15 D. J. Wasylenko, C. Ganesamoorthy, M. A. Henderson, B. D. Koivisto, H. D. Osthoff and C. P. Berlinguette, J. Am. Chem. Soc., 2010, 132, 16094-16106.

16 D. J. Wasylenko, C. Ganesamoorthy, B. D. Koivisto, M. A. Henderson and C. P. Berlinguette, Inorg. Chem., 2010, 49, 2202-
2209.

17 L. X. Xue, T. T. Meng, W. Yang and K. Z. Wang, Journal of Photochemistry and Photobiology B: Biology, 2014, 152, 95105.

18 J. J. Concepcion, J. W. Jurss, M. K. Brennaman, P. G. Hoertz, A. O. T. Patrocinio, N. Y. Murakami Iha, J. L. Templeton and T. J. Meyer, Acc. Chem. Res., 2009, 42, 1954-1965.

19 S. Romain, L. Vigara and A. Llobet, Acc. Chem. Res., 2009, 42, 1944-1953.

20 M. Schilling and S. Luber, Frontiers in Chemistry, 2018, 6, 100.

21 L.-P. Wang, Q. Wu and T. Van Voorhis, Inorg. Chem., 2010, 49, 4543-4553.

22 R. Matheu, M. Z. Ertem, J. Benet-Buchholz, E. Coronado, V. S. Batista, X. Sala and A. Llobet, J. Am. Chem. Soc., 2015, 137, 10786-10795.

23 T. Fan, S. Zhan and M. S. G. Ahlquist, ACS Catal., 2016, 6, 8308-8312.

24 L. Duan, F. Bozoglian, S. Mandal, B. Stewart, T. Privalov, A. Llobet and L. Sun, Nat. Chem., 2012, 4, 418-423.

25 L. Duan, C. M. Araujo, M. S. G. Ahlquist and L. Sun, Proc. Natl. Acad. Sci., 2012, 109, 15584-15588.

26 L. Wang, L. Duan, Y. Wang, M. S. G. Ahlquist and L. Sun, Chem. Commun., 2014, 50, 12947-12950.

27 J. Nyhlén, L. Duan, B. Åkermark, L. Sun and T. Privalov, Angew. Chemie - Int. Ed., 2010, 49, 1773-1777.

28 Q. Zeng, F. W. Lewis, L. M. Harwood and F. Hartl, Coord. Chem. Rev., 2015, 304-305, 88-101.

29 D. Scherrer, M. Schilling, S. Luber, T. Fox, B. Spingler, R. Alberto and C. J. Richmond, Dalt. Trans., 2016, 45, 1936119367.

30 M. Gil-Sepulcre, M. Böhler, M. Schilling, F. Bozoglian, C. Bachmann, D. Scherrer, T. Fox, B. Spingler, C. GimbertSuriñach, R. Alberto, R. Bofill, X. Sala, S. Luber, C. J. Richmond and A. Llobet, ChemSusChem, 2017, 10, 4517-4525.

31 L. Vilella, P. Vidossich, D. Balcells and A. Lledos, Dalton Trans., 2011, 40, 11241-11247.

32 R. Ahlrichs, M. Bär, M. Häser, H. Horn and C. Kölmel, Chem. Phys. Lett., 1989, 162, 165-169.

33 M. Gil-Sepulcre, J. C. Axelson, J. Aguiló, L. Solà-Hernández, L. Francàs, A. Poater, L. Blancafort, J. Benet-Buchholz, G. Guirado, L. Escriche, A. Llobet, R. Bofill and X. Sala, Inorganic Chemistry, 2016, 55, 11216-11229.

34 Q. Daniel, P. Huang, T. Fan, Y. Wang, L. Duan, L. Wang, F. Li, Z. Rinkevicius, F. Mamedov, M. S. Ahlquist, S. Styring and L. Sun, Coord. Chem. Rev., 2017, 346, 206-215.

35 L. Yan, R. Zong and Y. Pushkar, J. Catal., 2015, 330, 255-260.

36 D. D. Vito, H. Sidorenkova, P. Rotzinger, J. Weber, E. Merbach, Q. E. Ansermet and C. Gene, 2000, 5547-5552.

37 X. Sala, M. Z. Ertem, L. Vigara, T. K. Todorova, W. Chen, R. C. Rocha, F. Aquilante, C. J. Cramer, L. Gagliardi and A. Llobet, Angew. Chemie Int. Ed., 2010, 49, 7745-7747.

38 L. Tong, L. Duan, Y. Xu, T. Privalov and L. Sun, Angew. Chemie Int. Ed., 2011, 50, 445-449. 
39 L. Duan, L. Wang, A. K. Inge, A. Fischer, X. Zou and L. Sun, Inorg. Chem., 2013, 52, 7844-7852.

40 L. Wang, L. Duan, B. Stewart, M. Pu, J. Liu, T. Privalov and L. Sun, J. Am. Chem. Soc., 2012, 134, 18868-18880.

41 P. Sabatier, La Catalyse En Chimie Organique, Librairie Polytechnique: Paris et Liège, 1920.

42 C. Öğretir, D. Özöğüt, S. Yarligan and T. Arslan, J. Mol. Struct. THEOCHEM, 2006, 759, 73-78.

43 M. Taagepera, Henderson W. G., R. T. C. Brownlee, J. L. Beauchamp, D. Holtz and R. W. Taft, J. Am. Chem. Soc., 1972, 94, 1369-1370.

44 R. Kang, K. Chen, J. Yao, S. Shaik and H. Chen, Inorg. Chem., 2014, 53, 7130-7136.

45 M. Schilling, G. R. Patzke and S. Luber, Journal of Physical Chemistry C, 2016.

46 S. Zhan, D. Mårtensson, M. Purg, S. C. L. Kamerlin and M. S. G. Ahlquist, Angew. Chemie Int. Ed., 2017, 129, 70667069.

47 F. H. Hodel and S. Luber, ACS Catalysis, 2016, 6, 6750-6761.

48 M. Schilling, F. H. Hodel and S. Luber, ChemSusChem, 2017, 10, 4561-4569.

49 A. F. Abdel-Magied, A. Shatskiy, R. Z. Liao, T. M. Laine, W. A. Arafa, P. E. Siegbahn, M. D. Kärkäs, B. Åkermark and E. V. Johnston, ChemSusChem, 2016, 9, 3448-3456.

50 F. H. Hodel and S. Luber, ACS Catalysis, 2016, 6, 1505-1517. 